The Israeli Journal of Aquaculture - Bamidgeh, IJA_69.2017.1405. 9 pages

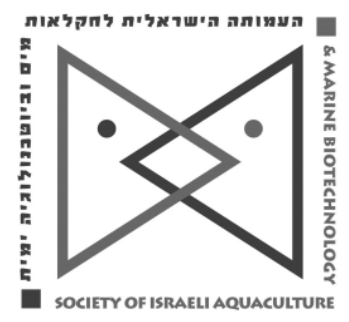

The IJA appears exclusively as a peer-reviewed on-line open-access journal at http://www.siamb.org.il. To read papers free of charge, please register online at registration form.

Sale of IJA papers is strictly forbidden.

\title{
Profitability Analysis of Monosex Tilapia Production under Three Culture Models in Hebei and Southern Coastal Provinces of China
}

\author{
Namatovu Safina 1, 3, Yuan Yongming1, 2*, Suakuani Andrew ${ }^{1}$, Shi \\ Pei ${ }^{1,2}$, Yuan Yuan 1, 2, Dai Yunyun ${ }^{1}$ \\ ${ }^{1}$ Wuxi Fisheries College, Nanjing Agriculture University, Wuxi, Jiangsu \\ 214081, China \\ ${ }^{2}$ Tilapia Industrial Research Center of China Agriculture Research System \\ ${ }^{3}$ National Fisheries Resources Research Institute, Aquaculture Research \\ and Development Centre, Kampala, Uganda 530
}

Keywords: Profitability analysis; tilapia production; culture models; China

\begin{abstract}
The purpose of this study was to understand and compare profitability indices of tilapia production under monoculture, polyculture, and integrated culture models. The study covered a total of 47 tilapia farmers in Guangdong, Guangxi, Fujian, Hainan, Yunnan provinces in the southern coastal areas, and Hebei province in Northern China. The study focused on two objectives: (i) Socioeconomic and production characteristics that influence tilapia production; (ii) Profitability indices, and breakeven analysis of tilapia production using a structured questionnaire. All calculations for the 3 culture models in this study are based on $1 \mathrm{mu}\left(667 \mathrm{~m}^{2}\right.$ or 0.666 ha). The study found that all tilapia farms visited were owned by males. About $72.9 \%$ of the farmers were 30 to 50 years of age; $50 \%$ of the farmers had undergone vocational training. Tilapia farm production areas averaged $70.2 \mathrm{mu}(\sim 4.7$ ha) per farmer, and pond aquaculture accounted for $87.5 \%$ of their production. Tilapia production costs were an average of US\$1168.4 (1 yuan=US\$6.6). Positive Gross Margins (GM) and Net Incomes (NFI) were observed. Tilapia production was economically viable with positive Benefit Cost Ratio (BCR) of US\$0.24 in monoculture, and US $\$ 0.15$ in other culture models. Farmers with low yields, especially tilapia cultured in an integrated model were expected to sell fish at US\$0.93per kilogram to recover invested capital within a single production season averaging 6 months. Positive Returns on Investment (ROI) of US $\$ 0.22-0.15 / \mathrm{kg}$ were observed in monoculture and polyculture respectively. In conclusion, the study found that for farmers to increase tilapia production profit margins, tilapia stocking densities need to increase, especially under integrated culture, and improvements are needed in fish feed utilization to reduce current feed conversion ratios (FCR). In order to boost sales, farmers must ensure production of quality fish, and seek alternative markets such as Africa.
\end{abstract}

* Corresponding author. YUAN Yongming, Tel.13961811962 yuan@ffrc.cn,

The first author: Namatovu Safina, +8618151531760 namatovusophi@yahoo.com 


\section{Introduction}

Aquaculture production is the fastest growing sector that has surpassed global capture fisheries supply, with a total of 73.3 million tons of aquatic products including fin fish, molluscs, crustaceans, amphibians, and aquatic plants supplied in 2014 (FAO 2016). China alone supplies over $60 \%$ of the total global aquatic production. Carp, salmon, and tilapia species (all Cichlids) have emerged as the most traded aquatic products worldwide. Tilapia is the second largest cultured species in over $85 \%$ of the tropical and sub-tropical countries (FAO 2002). In 2008 tilapia production was recorded at $13.4 \%$ (FAO 2010), and tilapia is expected to become one of the major global animal protein sources due to the growth of middle income class. China's aquaculture sector development stood at an annual growth rate of $7 \%$ between 2000-2014, exceeding that of capture fisheries (Yuan 2017). China exported about 1.4 million tons of tilapia products to the United States (USA), European Union (EU), and Japan in 2013 (Sustainable fisheries project 2015). The introduction of tilapia production in China began in 1957 with the introduction of original strains of mossambicus, aureus, and orchromise from Vietnam, Japan, Sudan USA, and Philippines. Uncontrolled tilapia reproduction, and early maturation affected growth performance (Lai 2003). The introduction of tilapia, and genetics research, has led to wide spread adoption of monosex tilapia production, namely orchromise and its hybrids, the GIFT strains, and Red tilapia which together account for $80-90 \%$ fish culture in southern China. These tilapia strains have uniform sizes and are fast growing within short culture periods; they are also disease resistant compared to mixed sex tilapia ( $\mathrm{Li}$ 2000). The rapid tilapia industrial development is also attributed to favorable climatic conditions especially in the southern coastal areas of China, strong government support for research, and technology development. In addition, tilapia species characteristics that allow high stocking densities, short culture periods, ease of culture, and are prolific, have attracted production by several farmers. Tilapia production in China is largely practiced in ponds and tanks cultured as a single species under monoculture, polyculture, and integrated culture models. Polyculture and integrated culture are China's traditional culture models dating back 2000 years (Chen 1995). Polyculture includes the culturing of different species like carp (Bighead, silver carp, and Grass carp), tilapia, and catfish among others. In polyculture, monosex tilapia were stocked based on ratios of $(2: 2: 1)$ with catfish and filter feeding carp to ensure efficient feed utilization. The integrated culture model involves tilapia production in rice paddies or with ducks. These two traditional culture models have been widely adopted on large scale for increased fish and food production with fewer antibiotics and artificial fertilizer application, environmental conservation in terms of self-cleaning systems for efficient water quality management, and fish feed utilization. Monoculture refers to the farming of a single species in different production systems. This culture model was introduced as a result of introduction of exotic species like tilapia and increased pressure for aquaculture intensification due to the growing demand for food fish. The model has contributed to increased volume of tilapia and global supply. China experienced a slight decline from 65 to 62 percent of its tilapia global supply (Hanson 2011). This decline has been attributed to the appreciation of the USA dollar $(\$)$ against RMB $(¥)$, and competition from other tilapia producing countries like Indonesia, Vietnam, and the Philippines where their global share increased to $54 \%$ by 2014 (Food and Agriculture organization 2016). Despite these challenges, China has remained a major producer and exporter of tilapia products.

Profitability analysis. This has been widely adopted to estimate overall efficiency of enterprises in relation to inputs and outputs (Engel 2010). The increased pressure on the aquaculture sector from other competing agriculture sectors in the form of investment prioritization has led to the application of different accounting techniques that enable a better monitoring of production technologies and ensures efficient resource utilization. However such publications are relatively rare in aquaculture (Natale 2011). The profitability approach utilizes both qualitative and quantitative data to draw comparisons in terms of viability of enterprises both short and long term (Ugwumba 2010). Application of Gross Margins (GM) that gained popularity in the 1960 s as one of the powerful economic tools used in profit analysis

(http://www.investopedia.com/terms/g/grossmargin.asp) compares economic 
performance in enterprises with similar characteristics. Net farm income (NFI) analysis is used in this study to measure profitability of tilapia enterprises. Benefit cost ratio (BCR) was applied to establish the short and long term economic viability of tilapia enterprises because some firms are profitable in a short run yet not economically viable in the long one. The viable enterprise shows how effective generated revenues can cover production costs (Emokaro 2010). Return on Investment (ROI) compared production costs in relation to benefits gained from tilapia production within in a given time frame. A few studies done on tilapia industrial development focused on the general economic analysis (Matlala 2013, Yuan 2017). However, this study focuses on profitability analysis of monosex tilapia production under three different culture models namely monoculture, polyculture, and integrated. These models were comprehensively studied to provide an in-depth understanding on profitability indices of tilapia production in Hebei and Southern coastal provinces of China.

\section{Materials and Methods}

Study Area. The study was carried out in six provinces in the Southern coastal areas and Northern part of China covering a total of 46 tilapia producers. The study was carried out between the month of June to November 2016, in Guangdong (45.8\%), Guangxi $(27.1 \%)$, Hainan $(8.3 \%)$, Fujian (4.3\%), Yunnan 6.3\% in Southern China, and Hebei Province $(6.8 \%)$ in the North of China. These study areas were sampled to provide an insight into the economic performance and management practices of tilapia enterprises that other developing countries can learn from. Data used for economic performance of tilapia production included fingerling stocking density, production costs, and quantities of fish (tilapia) harvested in a single production period per mu $\left(667 \mathrm{~m}^{2}\right.$ or $\left.0.666 \mathrm{ha}\right)$ in each of the three culture models.

Data collection Sources: Primary data was obtained from farmers using a structured questionnaire that consisted of two sections: (i) Socio economic and production characteristics of tilapia enterprises; (ii) input and output production indices of tilapia enterprises. Data was collected from the fish farmers with the help of Chinese translators to guarantee quality of the information. Secondary data was obtained from journals, reports, and other documents relevant to the study. All calculations in this study are based on $1 \mathrm{mu}\left(667 \mathrm{~m}^{2}\right.$ or $\left.0.666 \mathrm{ha}\right)$ under three culture models namely monoculture, polyculture, and integration.

Data Analysis: Socio-economic data was analyzed using descriptive statistics and presented using averages and percentages. Profitability data was calculated using different formulas and equations (O'Rourke 1996, Engel 2010, Thompson 2014) below:

Gross Margin Ratio (GMR)

$G M=T R-T V C$

Where GM is the Gross Margin, calculated from total Revenues (TR) calculated from average tilapia yield multiplied by average fish prices. The total variable costs (TVC) included production costs of Feed, Seed, Labor, Rent, Electricity and others.

Net farm incomes. These were calculated using both the Gross margin and fixed costs of Aerators, water pumps, and Automatic feeders.

$N F I=G M-D C$

Where NFI is the Net farm income, GM is the gross Margin, and DC is the depreciated capital of all the fixed costs. The equipment depreciated included aerators, automatic feeders, and water pumps with their average life span of 5.3, 4.1 and 4.9 years respectively. All the fixed costs were depreciated using straight line depreciation method (O"Rourke 1996)

Depreciation of fixed cost $=\frac{\text { purchase cost of equipments }}{\text { salvage life of equipments }}$ 
Benefit Cost Ratio (BCR). BCR was calculated using a discount factor (DF) of $16.6 \%$ calculated from the given interest rate of $6 \%$ charged on agricultural loans. This interest rate was charged on loans payable within a grace period of 6 months to 1 year, by all the individual borrowers from Agriculture Bank of China (ABC 2016). The discount factor equation is stated below as:

Discount factor $(D F)=\sum_{i=1}^{n} \frac{1}{(1+r)^{n}}, \mathrm{r}=$ interest rate and $\mathrm{n}$ is the time lag

Discount factor $=\frac{1}{(1+r)^{n}}=\frac{1}{(1+0.06)^{1}}=\frac{1}{1.06}=16.6 \%$

The discount factor of $16.6 \%$ was used to discount both the benefits (fish revenues) and production costs, and these were divided to get the Benefit Cost Ratio value as indicated in the equation below.

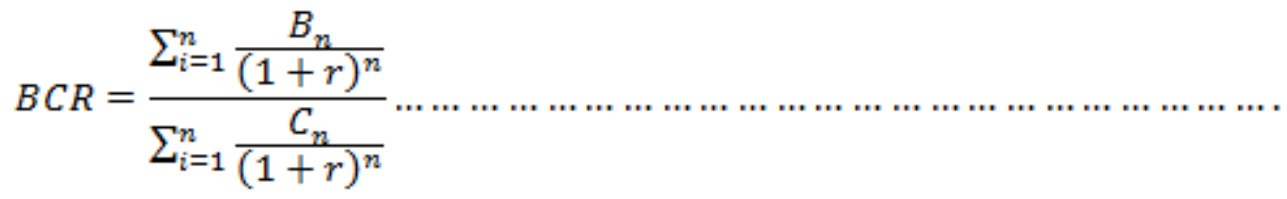

Where $B_{n}$ refers to benefits received from tilapia sales in a single production period that lasted for an average of 7 months for the three culture models. $n$ denotes the time lag in which the expected benefits were likely to occur from the time of investment (Joseph 2009)

Return on investment (ROI). ROI of tilapia production was calculated using net farm incomes (NFI) divided by total production cost (TPC). Return on investment was taken into consideration to compare tilapia culture models with high returns on investment during the production period.

$$
\text { Return On Investment }=\frac{N F I}{T P C}
$$

Break even analysis (BEA). BEA was calculated to evaluate feasibility of tilapia production within a shortest time frame. BEA enables us to understand what is required for an enterprise in terms of yield and average selling price to recover production costs. and keeps the enterprise focused in terms of production and marketing of its outputs (Rob Holland 1998)

$$
\text { Break even Yield }=\frac{T P C}{P X}
$$

Where TPC is the total production cost (variable costs+ depreciated capital), and PX denotes to average tilapia price

$$
\text { Break even Price }=\frac{T P C}{\text { Yield }}
$$

Where TPC is the total production costs that include both variable costs + discounted fixed costs, which are divided by the yield.

\section{Results}

Socioeconomic characteristics. All 46 farms sampled in the study areas were owned by males, and some of these male farmers worked with their spouses in the general farm management. Gender imbalance within the aquaculture sector does not only affect China, but cuts across rural aquaculture. On average, $89 \%$ of the respondents were married while young males of less than 30 years were single. $63.9 \%$ of the fish farmers had $3-4$ household members. About $50 \%$ of the fish farmers had a vocational training, and $33.3 \%$ of the farmers had primary education levels. An average of $58.3 \%$ tilapia farmers had between 5-10 years' experience in aquaculture production. This indicates the importance 
of the aquaculture industry as a source of livelihood in many rural communities in China. $72.9 \%$ tilapia farmers were 30-50 years (Table 1). Such an age group implies that aquaculture development in China suits all ages. The study identified the need for the continuous integration of modern technologies into tilapia industry to make work less strenuous, and attractive to youth.

Table 1: Statistics on socio economic characteristics of tilapia enterprises

\begin{tabular}{ll|ll}
\hline Production systems & Percentage & Farmer Education & Percentage \\
\hline Outdoor ponds & 85.1 & None & 2.1 \\
Indoor ponds & 6.4 & Primary & 34.0 \\
Reservoirs & 8.5 & University & 12.8 \\
Culture practices & & Vocational & 51.1 \\
Integrated & 14.9 & Aquaculture training & \\
Polyculture & 46.8 & Formal training & 53.2 \\
Monoculture & 38.3 & No training & 46.8 \\
Farmer Age & 4.3 & Aquaculture experience & \\
$<30$ & $<5$ & 8.5 \\
30 to 50 & 72.3 & 5 to 10 & 55.3 \\
$>50$ & 23.4 & 11 to 15 & 14.9 \\
& & $>15$ & 21.3 \\
\hline
\end{tabular}

The above parameters defined tilapia producers in the six provinces based on $1 \mathrm{mu}(0.66 \mathrm{ha})$

Production Characteristics of tilapia enterprises. Outdoor pond based aquaculture production accounted for $89 \%$ of tilapia production in the study areas. Areas used for fish production in the farms averaged $158.3 \mathrm{Mu}$ (158 ha); of this amount, $60.7 \mathrm{Mu}(0.444 \mathrm{ha})$ were for tilapia production. Aquaculture farmers in these provinces (51\%) had larger ponds of $15.5 \mathrm{Mu}(1.03 \mathrm{ha})$, and $30 \%$ of the respondents had ponds of more than 40.8 Mu (2.7 ha). About $49 \%$ of the individual farmers owned an average of 6 ponds. Tilapia (Monosex) with stocking densities ranged from 2734/0.6666 ha in monoculture, to $1521 / 0.66$ ha in integrated culture (Table 2). The average size of the monosex tilapia fingerlings was $2-4 \mathrm{~cm}$. Variations in fingerling prices were highly influenced by fingerling size and province location. For example, the polyculture model required large, and more expensive fingerlings of about $4 \mathrm{cms}$ to increase survival when stocked with canivorous species such as catfish.

Table 2: Statistical summary of tilapia production characteristics

\begin{tabular}{llll}
\hline Parameters & Monoculture & Polyculture & Integrated** \\
\hline Stocking Densities (pcs per & & & \\
mu) & $2,734.5$ & $1,845.8$ & $1,521.4$ \\
Fingerling prices (RMB) & 0.08 & 0.02 & 0.05 \\
Culture period (Month) & 6.6 & 6.6 & 7.2 \\
Feed conversion Ratio (FCR) & 1.4 & 1.3 & 1.38 \\
Survival rate (\%) & 87.9 & 88.9 & 89.8 \\
Harvest size (kg) & 0.75 & 0.75 & 0.72 \\
Sale prices (RMB/kg) & 1.6 & 1.4 & 1.2 \\
Yield(kg) & $2,252.7$ & 1,556 & 945.9 \\
\hline
\end{tabular}

The above calculations are tilapia stocking densities based on $1 \mathrm{mu}(0.66 \mathrm{ha})$ among three culture models. Tilapia production in polyculture was cultured with carps (Big head, common carps, silver carps and grass carps) and catfish. Under the integrated culture model tilapia was cultured in rice paddies or stocked with ducks. The variation in fish prices were as a result of small sized fish especially from the integrated culture model. The FCRs in polyculture were calculated based on the stocking ratios.

The feed conversion ratio (FCRs) used in this study were averages provided by the farmers to produce $1 \mathrm{~kg}$ tilapia in a single production season. In polyculture FCR was calculated based on stocking ratios of different fish species that included carp, mandarin fish, and catfish among others. The cost of feeds ranged from US $\$ 0.2$ for mixed culture and US\$0.21 in monoculture. Variation in FCRs was attributed to differences in stocking densities and farm management practices. On average, the cost of $1 \mathrm{~kg}$ tilapia was US\$1.24- US\$1.57 (farm gate price) in monoculture, and polyculture practices repectively. Tilapia produced in monoculture systems was of high quality and uniform sizes as compared to the tilapia produced in polyculture and intergrated culture model. Variation in tilapia prices were further influenced by farmer membership in cooperatives and direct fish production for processing companies. The drop in tilapia prices ranged from US\$1.8- US\$2.27 per kilogram (Fitzsimmons 2006). However polyculture and 
intergrated culture models have been noted to be the most effective models for growing organic food and fish, promoting efficient feed utilisation epecially when ponds are stocked with filter feed carp, and environmental conservation.

Input and output analysis of tilapia production. Fish feed accounted for an average of $75 \%$ of tilapia production costs in all the systems. Tilapia farmers in the integrated culture spent less on fish feed as compared to polyculture and monoculture farmers (Table 3). This variation in feed prices were influenced by tilapia stocking densities and the different management practices that led to high or low feed conversion ratios (FCR) for farmers. Tilapia fingerlings quality based on rate of growth, disease resistance, and fish size highly influenced seed costs. The study also noted that farmers who operated within cooperatives had comparative advantages over individual farmers, in terms of input purchases (seed and feed), and fish marketing due to higher bargaining power. Land rent prices varied across culture models ranging from US\$57.6-US\$86.1 per mu based on province location. Full time labor was paid a monthly salary for daily management of the farm.

Table 3: Enterprise budgets for tilapia production under 3 culture models

\begin{tabular}{lccc}
\hline Parameters & Monoculture & Polyculture & Integrated \\
\hline Yield (Revenues) & 3549.7 & 2263.5 & 1175.3 \\
Variable costs (RMB) & 76.1 & 66.9 & \\
Seed & 934.2 & 769.5 & 53.2 \\
Feed & 75.4 & 86.2 & 687.4 \\
Rent & 79.2 & 81.2 & 57.6 \\
Labor & 67.4 & 33.5 & 43.4 \\
Electricity & 21.0 & 20 & 27.7 \\
Others & 1253.5 & 1057.3 & 12.9 \\
Total Variable costs & & & 882.2 \\
Fixed costs(RMB) & 224.2 & 224.2 & 224.2 \\
Aerators & 147.9 & 147.9 & 147.9 \\
Automatic feeders & 179.5 & 179.5 & 179.5 \\
Water Pumps &
\end{tabular}

All the above production costs were calculated in US $\$$, exchange rate $1 \mathrm{RMB}=$ US $\$ 6.6$ (Bank of China 2016). All the culture models were subjected to similar fixed costs since on average one of each of the inputs was used per Mu (0.66 ha) during the production process.

Profitability analysis of tilapia production. Tilapia total production costs (variable and fixed costs costs) for the different models was: US $\$ 1357.5$ for monoculture, US $\$ 1176.5$ for polyculture, and US $\$ 986.3$ for integrated culture. Fixed costs were depreciated using salvage life of 4.1 years for automatic feeders, 5.1 years for aerators, and 4 years for water pumps. All the tilapia culture models had positive gross margins and net farm incomes as indicated (Table 4). Tilapia farmers were in a position to recover the short and long-term production costs of investment. The differences in gross margins were influenced by tilapia stocking densities, survival rate, and tilapia sale prices (Table 2). Return on investment (ROI) of US $\$ 0.22$ was received for every US $\$ 0.15$ invested in monoculture production. However, these returns on investment tended to vary between US\$1.15- US\$0.03 with polyculture and integrated culture model respectively. Monoculture practice had the highest Benefit Cost Ratio (BCR) of US $\$ 0.28$ which indicated these tilapia enterprises were economically viable compared to polyculture and integrated culture models (Table 4). When comparing the three models in terms of profitability, tilapia production was more profitable and economically viable under monoculture practice. The average breakeven yield was $767.9 \mathrm{~kg}$ which tilapia farmers were expected to produce to recover all production costs. Farmers with a lower breakeven yield needed to sell their fish at relatively higher prices to recover production costs (Table 4). 
Table 4: Profitability analysis of tilapia enterprises under 3 culture models

\begin{tabular}{llll}
\hline Parameters & Monoculture & Polyculture & Integrated \\
\hline Revenue (\$ US) & 3549.7 & 2263.5 & 1175.3 \\
Total Variable costs & 1253.5 & 1057.4 & 882.3 \\
Depreciated Capital & 104.0 & 104.0 & 104.0 \\
$\begin{array}{l}\text { Total production costs } \\
\text { (TVC+TDC) }\end{array}$ & 1357.5 & 1161.4 & 986.3 \\
Gross Margins (TR-TVC) & 2192.2 & 1206.1 & 188.9 \\
Net Farm Incomes (GM-DC) & 2088.2 & 1102.1 & 84.9 \\
Return on Investment & 0.22 & 0.13 & 0.02 \\
(NFI/TC) & 16.6 & 16.6 & 16.6 \\
$\begin{array}{l}\text { Discount factor (DF) 16.6\% } \\
\text { Discounted Costs (TC/DF) }\end{array}$ & 81.7 & 69.9 & 59.4 \\
$\begin{array}{l}\text { Discounted Benefits } \\
\text { (GM/DF) }\end{array}$ & 132.0 & 72.6 & 11.4 \\
Benefit Costs Ratio & 0.24 & 0.15 & 0.03 \\
$\begin{array}{l}\text { (DGM/DTC) } \\
\text { Breakeven Analysis (BEA) }\end{array}$ & & & \\
Price (TPC/Yield) & 0.54 & 0.74 & 0.93 \\
Yield (TPC/PX) & 795.4 & 798.4 & 710.1 \\
\hline
\end{tabular}

All the calculations in this table are based on $1 \mathrm{Mu}(0.66 \mathrm{ha})$ and the formulas have been explained in the methods. The currency was converted from RMB to US \$, Where 1 RMB=6.6 $\$$ US (Bank of China 2016).

Farmer level characteristics: Aquaculture enterprises were owned by males with only one female involved in yellow catfish production in Guangdong province (Beibei 2016 (Beibei 2016). Since men are deemed to be the household heads it is likely that most of the household business are also headed by men. Improving gender inequality that exists in aquaculture production in China and elsewhere is still a global challenge for fisheries and aquaculture (Brummett 2010). The fact that commercial aquaculture is a capitalintensive business pushes average rural women out of business. Nevertheless, women are involved in processing and marketing of aquatic products and play a major role in supplementing household incomes and streamlining their financial independence. Farmer's level of education is in an important factor that allows the adoption of available modern technologies and information into tilapia enterprises.

Production characteristics. Polyculture and integrated culture models are the Chinese traditional models considered environmentally friendly; they are also considered to be a source of high quality rice, duck, and fish. These culture models were adopted as development strategies for combatting rural poverty, addressing household food security problems, and environmental conservation. Tilapia production is practiced in both indoor and outdoor systems. In the study areas $14.9 \%$ of the farmers who practiced monoculture mainly focused on massive tilapia production for processing and exports. However, monoculture practice involved high feed costs (see Table 4) resulted in higher feed conversion ratios (FCR) ranging from 1.3-1.4 (table 2). These FCRs are similar to global averages of 1.4 reported in Hainan Province (Tacon 2008). The continuous application of sinking feeds by most of the farmers in this study needs to be replaced with more effective procedures. A positive relationship was observed between higher stocking densities and farm yields (Table 4). Higher stocking densities yielded the highest biomass in both pond and cage systems (Islam 2006). However, these higher densities affect growth performance, efficient feed utilization (Abou 2017), and have significant effects on water quality.

Profitability analysis of tilapia production. Feed costs and stocking densities accounted for the highest production. Electricity was one of the most essential inputs required to run aerators and automatic feeders that contributed to productivity and profitability of tilapia enterprises. 
Gross Margins. Positive gross margins observed among production culture models indicated that most tilapia enterprises are able to recover their variable production costs (Emokaro 2010). Monoculture had the highest gross margins (Table 4) compared to the other two culture models. These gross margins were highly influenced by stocking densities, survival rates, tilapia prices, and proper management. Based on these results lower production cost, high fish prices, and shorter culture periods had a significant impact on farm revenues. Shorter culture periods enabled tilapia farmers to have more than one crop a year. Monoculture farmers reached Positive Net Farm Income (NFI). All the three culture models recovered total production costs, although farmers under integrated and polyculture models were left with smaller profit margins (Table 4).

Benefit Cost Ratio. A comparison of benefits and costs in the alternative culture models for tilapia production was conducted. Monoculture had a BCR of 1.6 higher than that of polyculture and integrated culture models. The positive BCR in the two culture models reflected the cost effectiveness of undertaking tilapia production in monoculture and polyculture. The lower BCR observed under integrated culture model was affected by the low tilapia stocking densities, and relatively high production costs which had implications on tilapia revenues. Benefit Cost Ratio of 1.0 is required for any enterprises to breakeven (Thompson 2014). It should be noted that polyculture and integrated culture models provide farmers with alternative options for production of quality fish and food while conserving the environment.

\section{Conclusion}

Production was both profitable and economically viable among the three culture models although very small profits were achieved by tilapia farmers using the integrated model. There is need for tilapia farmers to adopt better management practices to ensure efficient fish feed utilization, and to reduce the current feed conversion ratio (FCR) to minimize production costs. There is need for engaging women into tilapia production to improve women's financial independence. Introduction of new innovations (SMART Aquaculture) through mobile app based aquaculture management will attract younger people into the aquaculture industry.

\section{Acknowledgements}

This work was funded by the Tilapia Industry Early warning system project, Grant number CARS-49-09B under the Tilapia Industry Research Centre of China Agriculture System. The lead author is grateful to the Government of Peoples' Republic of China for the scholarship offer, under the Chinese Scholarship council (CSC) funded by the Ministry of Commerce (MOFCOM). The team is grateful to the bureau members in the different provinces who introduced us to the tilapia farmers. We would also like to thank all the tilapia farmers (in the 6 provinces) who willingly participated in this study. And finally we thank Mr. Hayford Agbekpornu and Mr. Barry Kamira (PhD), for their comments which improved the manuscript.

\section{References}

Abou Y, Fiogbe, ED and Micha JCA 2017. Preliminary assessment of growth and production of Nile tilapia, Oreochromis niloticus fed Azolla-based diets in earthen ponds. Appl Aquacult 19pp in press

Agriculture Bank of China 2016 "RMB deposits rates" China Huaneng Group. Agriculture Bank of China Forex Deposit rates

www.abcchina.com/en/default.him 2017-5-4

Beibei J., ST-Hilaire S., Kehar S, Ian A., Gardner A I., 2016. Farm level returns and costs of yellow catfish (pelteobargrus fulvidraco) aquaculture in Guangdong and Zhejing Provinces, China. Aquacult Rep 4(2016) 48-56pp

Brummett, R.E., Youaleu, J., Tiani, L. N., Kenmegne A.M., 2010 Women's traditional fishery and alternative aquatic resource livelihood strategies in southern Cameroonian Rain forests: Fish Manag Ecol 17:221-230pp 
Chen H., Hu B., Charles AT.1995. Chinese integrated fish farming: Comparative bio economic analysis. Aquacult Res J 26(2):81-94pp

Chiu A., luping L, Shujing G., Bai CJ., Fedor R., Lee N., 2013. Feed and fishmeal use in the production of Carps and tilapia in China. Aquaculture 2127-2134pp

Emokaro CO., Ekunwe PA., Achille A., 2010. Profitability and viability of catfish farming in Kogi state, Nigeria. Res J Agric Biol Sci 6 (3): 215-219pp

Engle. CR., 2010. Aquaculture economics and financing management and analysis (electronic version) Wiley Blackwell. A John Wiley \&Sons, Ltd, Publication ISBN 9780-08138-1301-1 (pbk: alk. paper) 274pp

FAO 2002 Fishery statistics Aquaculture production 90:2pp www.fao.org /fishery/statistics /programme/publication/all/en

FAO 2010 The state of world Fisheries and Aquaculture Rome, 2010. FAO Fisheries and aquaculture department.www.fao.org/docrep/013/i1820e.pdf.2011-1-27

FAO 2016. State of world Fisheries and Aquaculture 2016, Food and Agriculture organization of the United Nations, Rome.www.fao.org/3/a-i5555e.pdf

Fitzsimmons K., 2006. Tilapia production in China: Huge output balanced by huge consumption. Global aquaculture advocates 58-59pp

Hanson A., Cui H., Zou L., Clarke S., Muldoon G., Potts J., Zhang H., 2011. Greening China's Fish and fish products market supply Chains. International institute of sustainable development.

Islam MS., Rahman MM and Tanaka M., 2006. Stocking density positively influence the yield and farm profitability in cage aquaculture of sutchi catfish. Pangasius sutchi.

J Applied Ichthyol 22:441-445pp

Joseph LN., Maloney R. and Possingham,H.P. 2009. Optimal allocation of resources among threatened species: A project prioritization protocol. J Conserv Biol 23:328-338

Lai QM, 2003. Improving seed quality and studying high yield culture model of tilapia (J) Ocean and Fisheries 41-42 (Chinese)

Li JL. 2000. Introduction and research of blue tilapia in mainland China (J) Zhejiang Ocean University, Nat Sci 19 (3):261-265 (Chinese)

Matlala M.P., Kpundeh MD., Yongming Y., 2013. Production and marketing systems of farmed tilapia in China Int J Fish Aquac 5(2) 12-18pp

Naomasa E., Arita S., Tamaru C., Leung P., 2013. Assessing Hawaii's Aquaculture farm and industry performance Aquaculture economics and Management. Aquacult Econ Manag 17:184-207pp

Natale F., Fiore G., Hofherr J., 2011. Mapping the research on aquaculture. Abibliometric Analysis of Aquaculture Literature. Scientometric 90:983-999pp

O"Rourke PD, 1996 Economic Analysis for Walleye Aquaculture enterprises. Walleye culture manual. NCRAC culture series 101. North Central Regional Aquaculture Center. Centre publications office, Lowe State University Ames 371-384pp

Rob Holland., 1998. Breakeven Analysis. Cooperative extension work in agriculture and home economies, The University of Tennessee institute of Agriculture. https://ag.tennessee.edu/cpa/Information\%20Sheets/adc3.pdf

Sustainable Fisheries Project 2015 Sustainable Fisheries Partnership (SFP). Aquaculture improvement projects. http://www.sustainablefish .org/News/SFP-praisesongoing-work-on

Tacon AGJ., Metian M., 2008. Global overview on the use of fish meal and fish oil in industrially compounded aqua feeds: trends and future prospects Aquaculture 285:146$158 \mathrm{pp}$

Thompson OA., 2014. Profitability of selected ventures in catfish aquaculture in Ondo state Nigeria Fish Aquacult J 5 (2):96pp

Ugwumba RN. Okoh PC. Ike, Nnabuife ELC and Orji EC. 2010 integrated farming system and its effect on farm cash income in Awka south agricultural zone of Anambra state, Nigeria American-Eurasian J. Agric Environ 8 (1):1-6pp

Yuan Y., Yongming Y., Yunyun D., Yunchong G., 2017. Economic profitability of tilapia farming in China Aquacult Int 1-12pp ISSN 0967-6120 